\title{
How do the Undergraduate Students Use an Example in Mathematical Proof Construction: A Study based on Argumentation and Proving Activity
}

\author{
Christina M. Laamena ${ }^{1,2^{*}}$, Toto Nusantara ${ }^{3}$, Edy Bambang Irawan ${ }^{3}$, Makbul Muksar ${ }^{3}$ \\ ${ }^{1}$ Graduate Students of State University of Malang, INDONESIA \\ ${ }^{2}$ Mathematics Education, Pattimura University, Ambon INDONESIA \\ ${ }^{3}$ Mathematics Department, State University of Malang, INDONESIA \\ * CORRESPONDENCE: \ christina.1403119@students.um.ac.id
}

\begin{abstract}
Various studies have been conducted regarding the use of examples in a mathematical proof. This study aims to describe how the students use the example in the proof analyzed by argumentation and proving activity. Qualitative methods are used to explain the phenomena that arise in the use of examples on mathematical proof. The data collected is the result of student work, think aloud, field notes and interview results. The results show that the example is used as an exploratory tool, an example as an investigative tool for justification and an example as a conviction tool. In Toulmin's view, examples as explorers serve as data, examples as an instrument of investigation for justification serve as warrant and backing while the example as a conviction tool serves as a qualifier to convince them of the resulting claim. An example as an investigative tool for justification produces two types of argumentation structures: argument structures consisting of one cycle and two cycles. An example of an exploratory tool serves as a data form of simple argumentation. Examples play an important role in mathematical proof although the example is not deductive proof. Examples can be used with various functions depending on the student's needs.
\end{abstract}

Keywords: example, mathematical proving, argumentation, Toulmin' argumentation, proving activity

\section{INTRODUCTION}

The vital role of students in learning for example has always received attention (Iannone et al., 2012). Mathematicians say that the experimental process for example is an important aspect of proving development (Epstein \& Levy, 1995). Various studies have been conducted regarding the use of mathematical proofs at various levels of education. Use of examples on student proving (Cañadas, Castro, \& Castro, 2009; Ellis et al., 2012; Reid, 2002); by prospective and teacher (Nardi, Biza, \& Watson, 2014; Nardi, Biza, \& Zachariades, 2012) and by mathematicians (Alcock \& Inglis, 2008; Inglis, Mejia-ramos, \& Simpson, 2007; Inglis \& Mejia-Ramos, 2010). Epstein and Levy (1995) argue that "many mathematicians spend a great deal of time thinking and analyzing specific examples" and have the most significant effect, all beginning with experimentation based on examples.

There are several types of mathematical proofs. Balacheff (1988) presents four types of examples used by students in proof: (1) Naive empiricism, which is to confirm the truth of the statement after verifying some

Article History: Received 11 June $2018 \bullet$ Revised 30 June $2018 \bullet$ Accepted 12 July 2018

(C) 2018 The Author(s). Open Access terms of the Creative Commons Attribution 4.0 International License (http://creativecommons.org/licenses/by/4.0/) apply. The license permits unrestricted use, distribution, and reproduction in any medium, on the condition that users give exact credit to the original author(s) and the source, provide a link to the Creative Commons license, and indicate if they made any changes. 
special cases; (2) The crucial experiment is an example used to choose between two hypotheses based on experiments (whether experiments causing the rejection of one hypothesis or not), the experiment uses the same statement or symbol for a process with very little difference; (3) The generic example is an example used to clarify reasons for the truth of statements, such as specific traits and structures; (4) The thought experiment is to internalize the experiment and separate it from special representations. The operations and relationships underlying proof are indicated in several ways rather than with the results that have been used. In addition, Mason and Watson (1984) proposed the term boundary example that is the use of examples that are only 'temporary' to find the special properties and eliminate things that are not needed and then shift to deductive proof.

The use of examples can be seen as an implicit part of inductive reasoning (Watson \& Mason, 2005) which generally begins with special cases to obtain as much information (Conner, Singletary, Smith, Wagner, \& Francisco, 2014). Although proving requires a special form of reasoning that is deductive reasoning, other reasoning such as inductive reasoning is also needed. Examples of proving are used to; (1) understand mathematical statements or understand the proof process being read (Ellis, Lockwood, Williams, Dogan, \& Knuth, 2012); (2) exploring problems for constructing conjectures or hypotheses (Buchbinder \& Pedemonte, 2011; Conner et al., 2014); (3) illustrating new techniques and ideas; (4) identifying general patterns for the generalization process (Watson, \& Mason, 2005) and (5) verifying the results obtained (Balacheff, 1988).

Examples are at the intersection 'between general and special' (Buchbinder \& Pedemonte, 2011) which play a role in concrete abstract mathematical ideas (Watson \& Mason, 2005). Example-based reasoning strategies can lead to important opportunities, clarifying ways that can be used to support student proof development (Lockwood et al., 2013). This study aims to describe the role of an example based on mathematical proof activity and its position in Toulmin's argumentation component to validate the conjectural truth and produce true claims and their implications on the resulting argumentation structure.

\section{Activity in Mathematical Proving}

Inglis and Mejia-Ramos (2010) say that, "there are various activities conducted by students as well as mathematicians related to argumentation and proving". Giaquinto (2005) suggests that, "for every mathematical activity, there are three interrelated general activities: producing, presenting, and taking in". In the context of proof and argument, these three general activities are correspondent to constructing a novel argument, presenting an available argument, and reading it (Inglis \& Mejia-Ramos, 2010). Constructing activities, presenting and reading arguments are done with different purposes. Argumentation can be aimed at convincing others about the resulting conclusions, explaining why the statement is true (false) or demonstrating the validity of the argument.

Bell's (De Villiers, 1990) describes five functions of mathematical proof: (1) Verification (pay attention to the truth of the statement), (2) explanation (give insight "why statements are true), (3) systematization (organize various results in logical deductive systems), (4) discovery (invention new result) and (5) communication (spreading mathematical knowledge). The Mejía-Ramos and Inglish (2008) study combined Giaquinto's mathematical activity and Bell's proving activity in sub-activities that are grouped as follows:

1. Constructing activity, consisting of exploring the problem, estimating the truth of the conjecture and justifying the truth of the claim

2. Reading activity, consisting of comprehensive reading of the evidence and evaluating evidence

3. Presenting activities, consisting of convincing the audience about the claim, explaining why the claim is right/wrong, demonstrating the validity of the argument

During problem-solving, arguments are used to generate conjectures and prove the truth of the conjecture. The comparison between arguments in favor of conjecture and proof is based on the hypothesis. That proof can be viewed as a special argument in mathematics (Buchbinder \& Pedemonte, 2011; Douek, 1999). Generally mathematical proof consists of non-singular arguments but in the form of structures used to convince others of conclusions (Aberdein, 2012). According to Boero, Garuti, and Mariotti (1996), during the production of conjecture, students work progressively through intensive argumentation that contributes to justifying their seemingly plausible decisions. Students relate the arguments in a coherent way to organize them based on previously generated arguments to form a logical chain. 


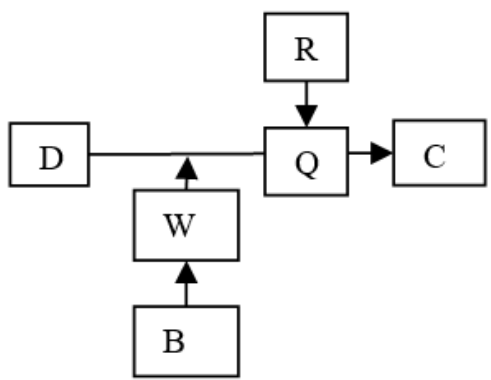

Figure 1. Model of Toulmin's Argumentation. The argument would read "D, and since W (given B) we can Q conclude $\mathrm{C}$, unless $\mathrm{R}$

Table 1. Description of Use of Example in Proof

\begin{tabular}{lll}
\hline Example Usage & $\begin{array}{l}\text { Toulmin's Argument } \\
\text { Component }\end{array}$ & Description \\
\hline Exploration tool & data & $\begin{array}{l}\text { Students explore facts in the given problem using } \\
\text { examples to understand the given proof problem }\end{array}$ \\
\hline $\begin{array}{l}\text { Investigation and } \\
\text { Justification Tool }\end{array}$ & Warrant and Backing & $\begin{array}{l}\text { The subject raises an example to estimate the truth } \\
\text { of the conjecture and justify the truth of the claim }\end{array}$ \\
\hline Conviction tool & Warrant and backing & $\begin{array}{l}\text { Students use examples to convince themselves of } \\
\text { claims that have been generated } \\
\text { The example used causes a qualifier change from } \\
\text { 'maybe' to 'sure' }\end{array}$ \\
\hline
\end{tabular}

\section{Toulmin' argumentation model}

Toulmin $(1958,2003)$ makes it possible to explain the structure of the argument that provides an opportunity for the use of example in conclusion. Toulmin's argumentation has been used to analyze the process of constructing the proof (Inglis et al., 2007; Knipping, 2004; Pedemonte, 2007), constructing the definition (Ubuz, Dincer, \& Bulbul, 2012) and solving the problem (Buchbinder \& Pedemonte, 2011; Ubuz, Dincer, \& Bülbül, 2013). Toulmin's argumentation is also used in describing the structure of individual arguments as well as collective arguments. This study focuses on the structure of individual constructed argumentation, so there is no teacher or friend intervention.

Toulmin's argumentation model (Toulmin, 2003) consists of three main components: data (D), claim (C) and warrant $(\mathrm{W})$ and three (3) complementary components: backing (B), rebuttal (R) and modal qualifier (Q). Toulmin's argument is depicted in the scheme as in Figure 1. Claims are statements made on the basis of data. Data is the 'foundation' of the argument based, facts relevant to the conclusion. Warrants such as 'bridges' that connect data and conclusions. A warrant is a rationale used to generate conclusions. This basic thought can take the form of formulas, definitions; make analogies, drawings or diagrams and graphs. Reasons are reinforced by backing (support) which is further evidence required. Modal Qualifier is the 'phrase' given to the conclusion to indicate the level of confidence in a conclusion, such as 'probably' or presumably, possibly. The rebuttal is a statement that refutes the resulting conclusion if there is an exception condition in which mathematical proof is called a counterexample.

Based on the content, arguments are called formal if warrants are based on definitions, axioms and theorems whereas if a warrant is based on concrete interpretation of concepts of mathematics including visual and other illustrative representations, it is called informal arguments (Knipping, 2004; Viholainen, 2011). Informal argumentation is also called inductive argumentation whereas formal argumentation is referred to as deductive argumentation (Inglis, Mejia-Ramos, \& Simpson, 2007; Knipping, 2003; Pedemonte, 2003). Cases are "special observations that meet the circumstances (Reid \& Knipping, 2010) that are part of an inductive or informal argumentation.

In this study, we will investigate the use of examples based on proving activities and relate it to Toulmin's argumentation. Based on Bell's proof, activity and the research results of Mejía-Ramos and Inglish, examples play role astools in some proving activities. Examples can serve as an exploration tool (explorations for understanding statements), as a tool of investigation and justification (to investigation and estimate the truth of the conjecture and justify the truth of the claim) and as a tool conviction (to test the results obtained, to verify the process of verification and to assure the truth of the claim). 


\section{RESEARCH METHODS}

This research is a qualitative research with phenomenological design that aims to explain the phenomenon use of examples that occur in the mathematical proving process viewed from Toulmin's argumentation and proving activities. In phenomenology design, data is collected not only through student work sheet, but also through in-depth interviews to analyze, identify, understand and explain the students' thinking processes underlying their reactions and perceptions (Fraenkel \& Wallen, 2003). This design is considered appropriate to describe the use of examples in argumentation on the mathematical proof process.

\section{Material}

The problem given is the problem of algebra that is a proven and misplanned statement of mathematics so that the student is expected to prove mathematically (proving) and find a counterexample which in the Toulmin's model is called rebuttal. Before using it in the study, this assignment sheet has been validated by experts. The tasks are given as follows:

1. Suppose the function $f: \mathbb{R} \rightarrow \mathbb{R}$ by the formula $f(x)=x^{2}$ and $g: \mathbb{R} \rightarrow \mathbb{R}$ by the formula $g(x)=x$. Investigate whether $f(x) \geq g(x)$ for all $x$ Real numbers?

2. Suppose a non-empty set of A. $f$ and $g$ is a function of A to A. If the function $f \circ g$ is one-one then $g$ functions one-one. Investigate, the truth of the statement!

\section{Participants, Subjek and Research Procedure}

Number of research subjects is 7 students of mathematics education program of Pattimura University of Ambon, Maluku Indonesia. The process of collecting data begins by providing a proof problem to 32 participants for individual completion; students who correctly answered the first problem are 8 people and 5 people for the second problem which then selected 7 people as research subjects. During work, students are asked to voice what is thought (think aloud). Students are given the opportunity to explore, write and say all their thoughts and ideas without being limited by time. They will be finished when they feel they are not able to finish it or have no idea anymore. During the problem solving, the researchers, observed and recorded all behaviors including think aloud students. Students are then interviewed individually to explain the process of thinking when constructing of proof. All data (observation, interview, think aloud and field notes) were analyzed and the researchers reduced things that were deemed unimportant. Based on the results of work and interviews with students, researchers decide of research subject. Analysis of interview results using a multi-case study approach developed by Bromley (1986).

\section{RESULT AND DISCUSSION}

There are two types of examples that students use in the process of constructing of proof. First, the examples of real numbers and the second example images to represent the functions of the composition and the one-to-one function. Both types of examples used have several functions, namely:

1. Example as an exploration tool

2. Example as an investigative tool for justification

3. Example as a convincing tool.

In view of Toulmin's component argument, these three functional examples may contribute to exploring the data, as a warrant and as backing affecting the qualifier.

\section{Example as an Exploration Tool}

The exploration process begins with a comprehensive reading activity that aims to understand the meaning of the statement and evaluate it based on known criteria (Mejía-Ramos \& Inglish, 2008) and occurs at the beginning of the proving process. Mason, Burton, and Stacey (2010) call this stage an entry phase characterized by "actual reading" and "discovering the real problem". The activity of reading and understanding of the problem is indicated by think aloud of the subject and validated by the observation result. The results of the observation indicate that, the student several times reads and repeats the data on the first problem, 'function composition and one-one function', and then make representation in the form of arrow diagram. In the interview, the students revealed that emphasis and visualization were done to 'clarify' abstract information making it easier to conduct an investigation. An example of an arrow diagram as a function 


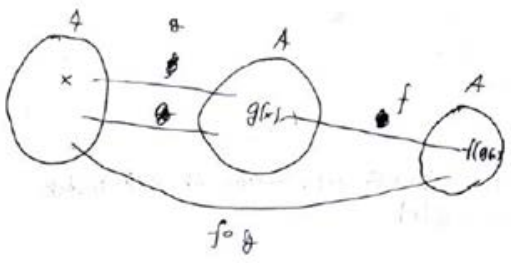

(a)

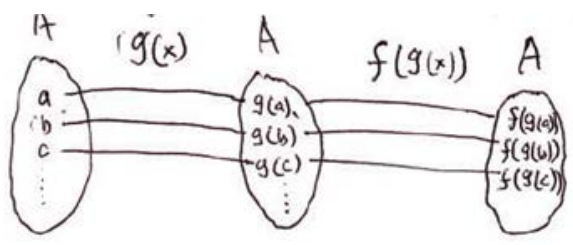

(b)

Figure 2. Subjects Work of Example as an Exploration Tool

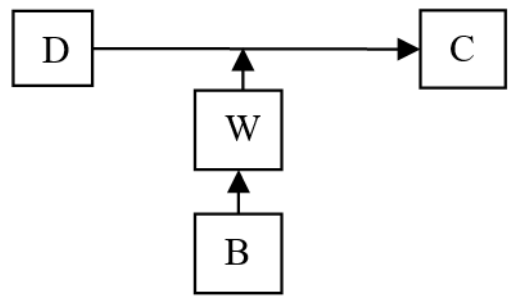

Figure 3. Argumentation Structure for Example as an Exploration Tool

representation is the thought experiment (Balacheff, 1988) that is to internalize the function of composition with special representation. Here, one example of student answers.

In Figure 2 it is clear that the subject uses an example to explore the information (data) it derives from the problem. Data on the problem, namely: (1) A set is not empty; (2) $f$ and $g$ are functions from $A$ to $A$; (3) $f \circ g$ one-to-one function; whereas the claim to be proved is 'are $g$ one-one function; being concretized by an example of an arrow diagram called Polya as 'elemen would be found' to understand the problem (Musser, Burger, \& Peterson, 2011)

Many students struggle to recognize, understand and produce deductive arguments (Harel \& Sowder, 1998) through an inductive argument as a bridge. Ellis et al. (2012) suggests that an important resource underlying the students' attempts to understand proof is their treatment of examples. On the other hand, careful example exploration is not explicitly supported as a strategy for developing deductive reasoning; students have little opportunity to analyze examples strategically in order to understand mathematical statements or to gain an 'insight' to develop proof. Examples are used during observation as empirical arguments to convince themselves (Harel \& Sowder, 1998) and are often performed by students from different levels of education.

An example of an exploratory tool plays a role in exploring the component data in Toulmin's argumentation and generating no claim or decision whether the statement is true or false. The warrant used is the inductive warrant (Inglis et al., 2007) with backing is the definition of the composition function and the one-one function required to make the illustration easier for the subject to understand the given problem. Based on the examples made, the subject eliminates some doubts on the statement and raises the 'suspicion' that the statement is true but has not made a claim. The resulting claim is still 'transient' by saying that ' $g$ will be shown as a one-on-one' function. The claim based on the use of examples as an exploratory tool is called Polya (Musser, Burger, \& Peterson, 2011) as the element asked while the data is what is known. The argument when the example is used as an exploratory tool can be described in the Toulmin's argumentation scheme (Figure 3) in the form of simple argumentation structure because it only consists of 3 main components i.e data, claims and warrant and 1 complementary component is backing.

\section{Example as an Investigation and J ustification Tool}

Investigation and justification are two different things but inseparable; the investigation leads to justification or justification based on the outcome of the investigation. An example as an investigative and justification tool is a condition in which the subject uses examples to investigate the truth of the statement and then justifying, declaring or deciding whether a statement is true or false. The investigation raises awareness about claims that might be generated later. Examples and calculations are the basis of the subject to justify. Investigations using examples can be repeated and generate some initial justification until the subject feels confident about the outcome of his investigation and makes the final claim or final justification. Some initial 


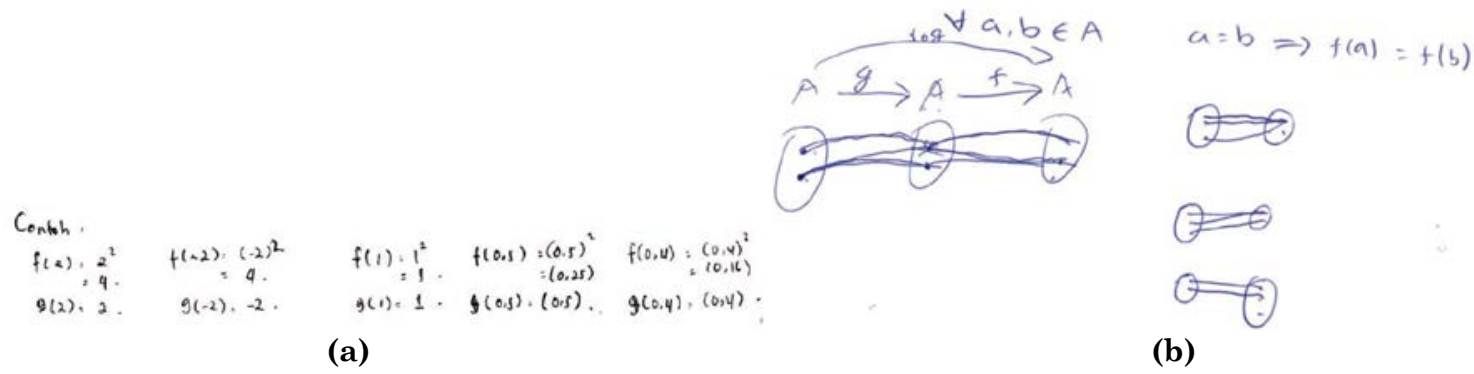

Figure 4. Subjects work of example as investigation and justification (justifications are implicit) a) Fanny' Work b) Kevin' Work

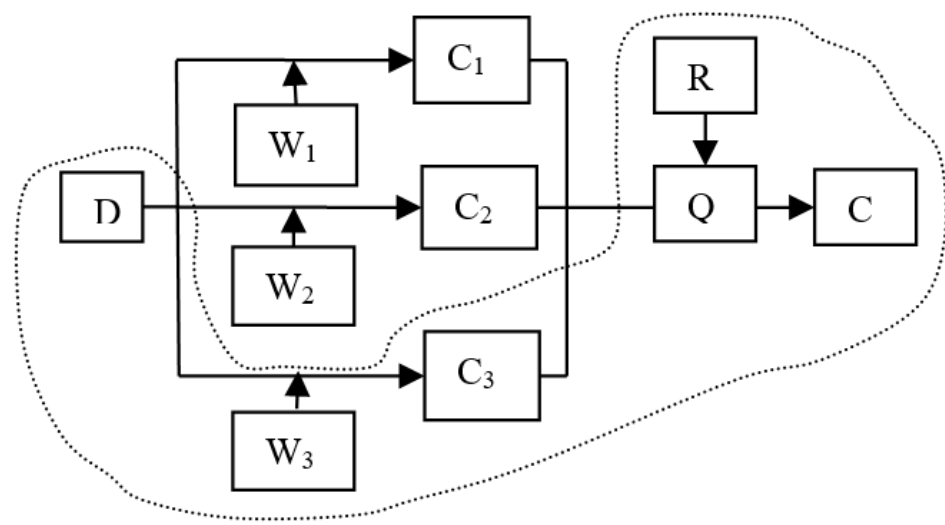

(a)

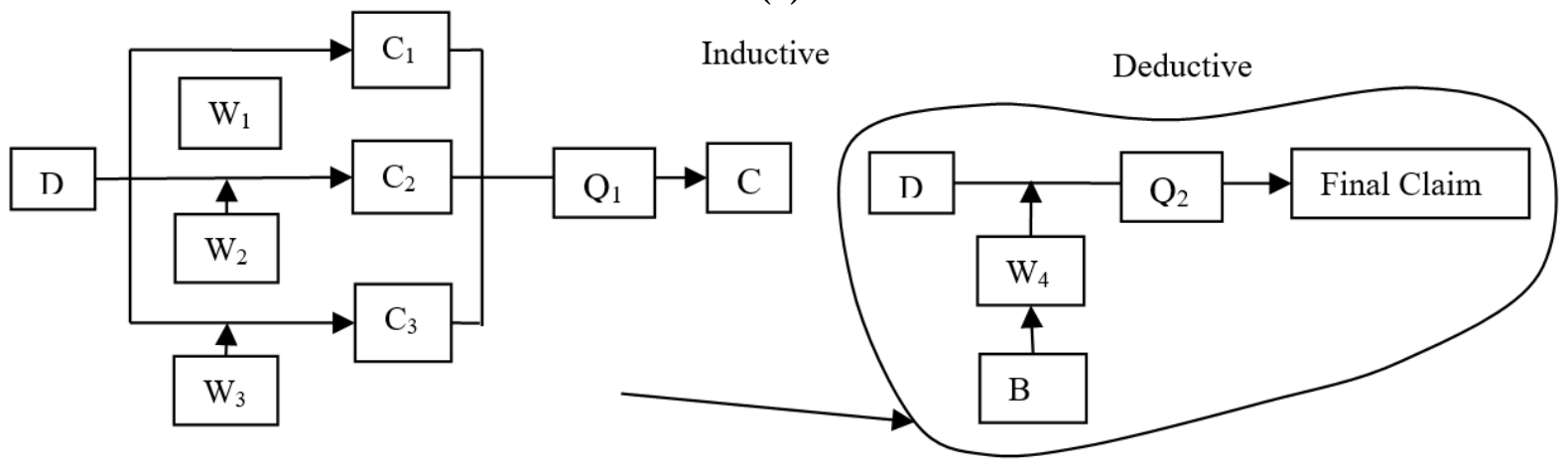

(b)

Figure 5. a) Argumentation Structure for disprove statement b) Argumentation Structure for prove statement

justifications are explicit (clearly written in subject work) or implicit (stored only in memory and not written on the work sheet). Implicit justification based on the example is known based on interview results.

According to Fanny (Figure 4a) "I take any real number, say $x=2 ; x=-2 ; x=1 ; x=0,5 ; x=0,4$; for $x=$ $2, f(2)=4$ dan $g(2)=2$ then $f(2)$ more than $g(2)$ so the statement is true $f(x) \geq g(x) \ldots$ but for $x=$ $0.5, f(0.5)=0.25$ and $g(0.5)=0.5$ then $f(0.5)$ less than $g(0.5)$ means $f(x)<g(x)$. Meanwhile, according to Kevin (Figure 5b) I try are true "if $f \circ g$ one-one then always $g$ one-one function', and it turns out right, I must prove.

Kevin realizes that the example is an inductive method which is unacceptable to its general conclusion, so the example is only used for conducting such an investigation and generating an initial claim or conjecture (Mason et al., 2010).The initial claim is used as the basis for using other deductive methods of proof. Justification may take the form of a claim, both initial claims (Mason et al., 2010; Reid, 2002) as conjecture and final claim to be verified. Subjects tend to investigate by using examples to look for possibilities that will appear and see patterns and then justify them. Fanny and Kevin investigations (Figure 4) resulted in some initial justification and final justification. Fanny's investigation provides a final justification that, the 


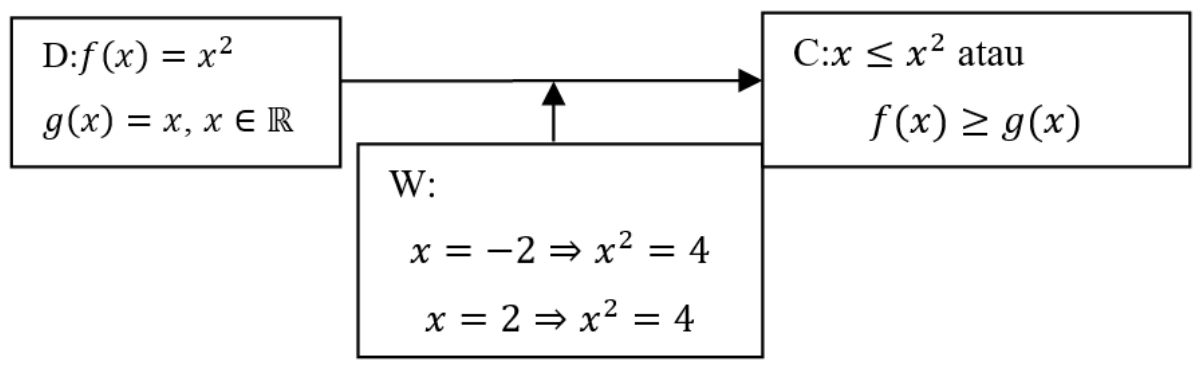

Figure 6. One of AS on Example as Justification Tool

statement is false because there are examples of denial that is $x=0.5$ which causes $f(x)<g(x)$. Kevin's investigation yields a temporary justification (conjecture) that the statement is true because the subject can not find the counterexample, so this conjecture is proved by Kevin and produces a final justification (claim) that the statement proves is true.

Based on the interview results, the investigation process is based on the 'investigate' instruction on the problem and is understood as 'trial and error' whether the statement is true or not. The investigation is carried out to look for examples that led to false or counterexample (Inglis et al., 2007) statements so as to justify that statement is false. For the first problem, the example causes the student to find the counterexample (rebuttal) so they used strong warrant inductive (Laamena, 2017); while for the second problem, the trial and error method does not generate a counterexample. Thus, the student concludes that the first statement is false and the second statement is true (so it must be proved).

According to Healy and Hoyles (2000), proof-based examples refer to some examples as justification stating that statements are true or false. Justification consists of two parts: justification based on special cases and justification based on generalizations on formal proof (Cañadas et al., 2009). Justification by special case puts the example as warrant while justification based on generalization puts the example as backing. Examples used as warrants are the process of drawing conclusions (claims) based on special cases, called disebut (Inglis et al., 2007; Knipping, 2003), as inductive warrants or informal warrants. Fanny and Kevin's answer (Figure 4) is an example of justification based on a special case that places the example as a warrant.

\section{Justification based on a particular case that places the example as a warrant}

At the time of the investigation, the subject uses examples based on specific cases and then uses the "trial and error' method. The 'trial and error' method occurs when the subject selects numerical examples, substitute into the function equation, calculates it and generates a claim, then repeats the same process until he feels confident that the selected examples already include all real numbers. Student argumentation structures that use instances as investigative and justification tools based on special cases for the first problem (False statements) can be explained by Figure 5a and Figure 5b for the second problem (true statement).

Examples are found in $\mathrm{W}_{1}, \mathrm{~W}_{2}$, and $\mathrm{W}_{3}$ and yield three initial claims of $\mathrm{C}_{1}, \mathrm{C}_{2}$, and $\mathrm{C}_{3}$. The circled argumentation stream (Figure 5a) is a final claim with $\mathrm{W}_{3}$ as a counterexample (R) and a qualifier is 'sure'. This happens because the subject has a perfect understanding of the proof of the false statement that they confidently (Q) make a claim. In Figure 5a it is seen that the investigation of special cases produces a final claim because in special cases there are examples of denial which are then used to state that the statement is false. While in Figure $\mathbf{5 b}$ a special case only produces a conjecture which is subsequently verified using a deductive warrant $\left(\mathrm{W}_{4}\right)$. The final claim (Figure 5b) is generated on the basis of analytic methods and deductive proof, in this case when using the example case as a warrant, the subject only reduces uncertain things rather than eliminating them (Inglis et al., 2007). Students with low abilities tend to use one type of warrant inductive warrant in the form of examples of real numbers (Laamena, Nusantara, Irawan, \& Muksar, 2018).

The student argument for generating a claim is based on some initial claim called Knipping (2003) as an argumentation stream (AS). Each initial claim is supported by an inductive warrant in the form of a example of numbers and calculations. Here's one of the first AS claims $\left(\mathrm{C}_{1}\right)$.

Justification based on generalization on formal proof, placing the example as backing. In this condition, the student investigates using deductive warrant, not an example (other inductive warrant or deductive warrant), but having difficulty to make justification (claim) requires an example to ease student make a claim. Thus, the example is used as a backing to facilitate students to make justification (claim). Based on the data 


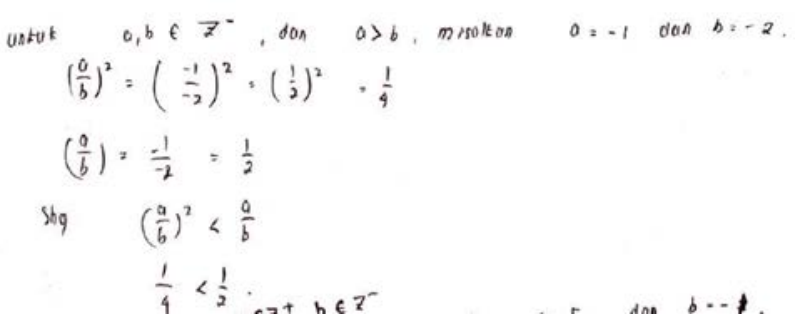

(a)

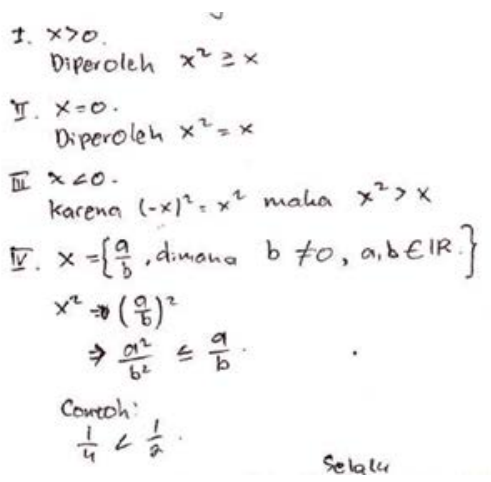

(b)

Figure 7. Student Work with Example as Justification Tool (Example as Backing) a) Example as the only Backing b) Example as one of Backing

obtained ( $x$ is a real number) students use the properties of numbers by grouping the real numbers into rational numbers as subsets of real numbers (warrant deductive), or integers (negative, positive and zero) and fractions. Selecting $x$ as a rational number, students write $x=\frac{a}{b}$ then group $x$ by value $a$ and $b$. Students can also classify real numbers into integers and fractions, but require example to make it easier for students to produce claims. Here's one of the student answers.

In the section example as the only backing, the process is repeatable for other cases, for example for $a<$ $b, a=b, a>b$; so as to generate argumentation structures with more than one AS and each AS constructed by deductive warrant with only backing example or deductive warrant with other backing plus backing example. While in the section example as one of the backing, the student uses an example of numbers only in the case of $x$ is fractions, another case can be referred based on the properties of the numbers. The causes of students using the example as a backing is because students have difficulty in determining the relationships $x^{2}$ and $x$. Here's an interview quote with one of the subjects using the example as backing after using the number properties (deductive warrant)

Interviewer: how do you get $a<b$ then $\frac{a}{b}<\frac{a^{2}}{b^{2}}$ ?

Merry: from here (pointing to her work). Because if I take $a=-1$ and $b=-2$ then $\frac{1}{2}>\frac{1}{4}$

Interviewer: why do you take $a=-1$ and $b=-2$ ?

Merry: because I want to decide which one is bigger, $\frac{a}{b}$ or $\frac{a^{2}}{b^{2}}$

Interviewer: is it not enough to decide with a and b only?

Merry: if with $a$ and $b$, it's hard maam, I can not, so I make it so

Subjects' argumentation when generating the claim for example used as justification tool can be explained by Toulmin' model as Figure 8. 


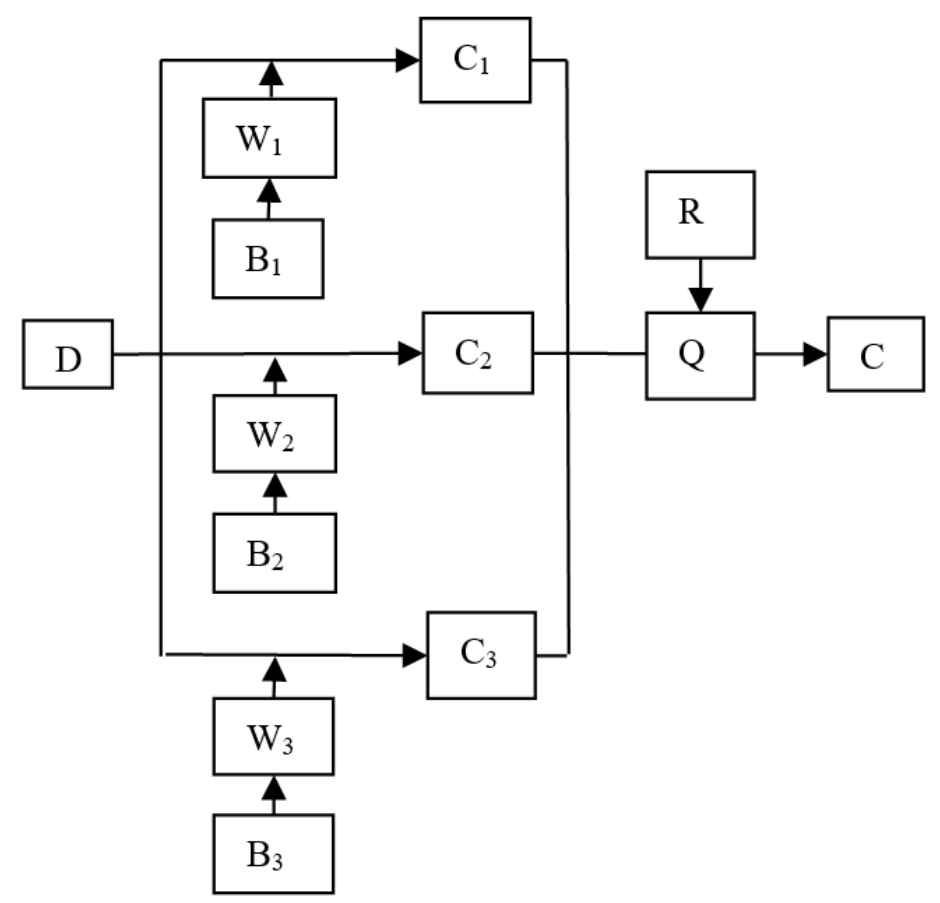

Figure 8. Student Argumentation on the Example as a Justification Tool (example as backing)

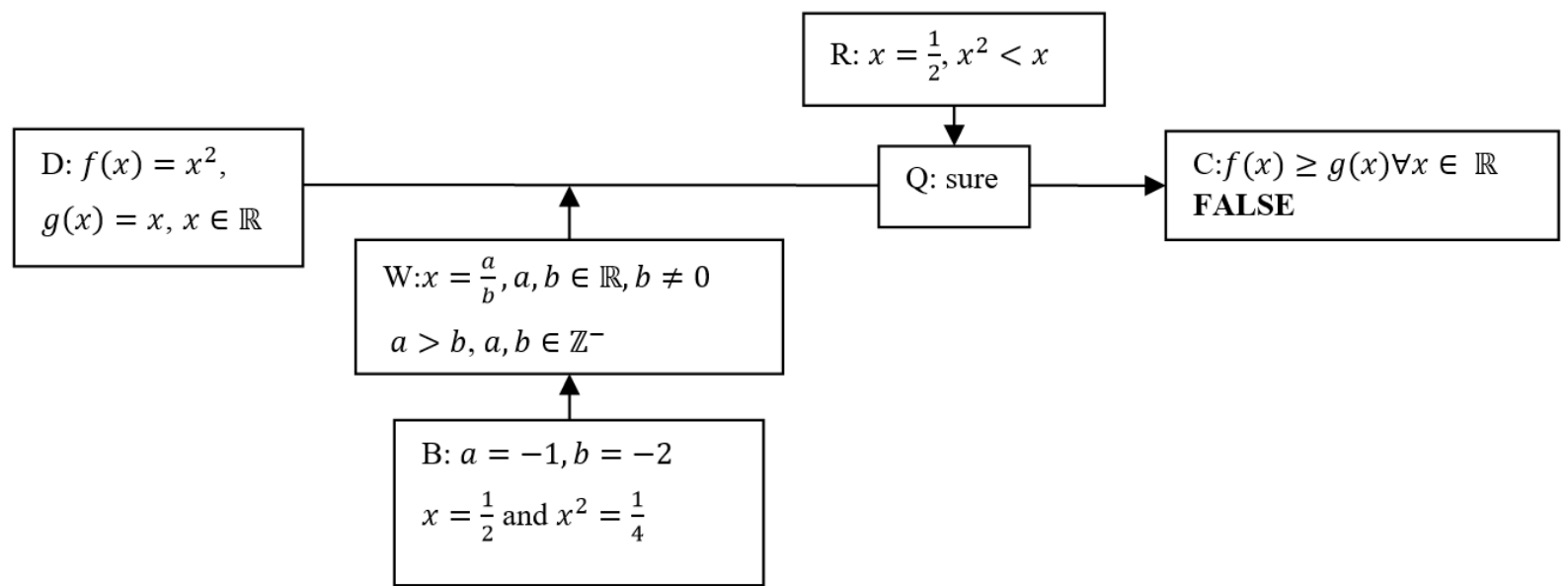

Figure 9. The One of Argumentation Stream with example as a backing for the final claim

The examples produced in Figures $4 \mathbf{a}$ and 7 are counterexample (rebuttal) used by students to refute or disprove the truth of the statement. Examples used (as warrant and backing) can produce rebuttal so that students conclude (claim) that the statement given is wrong. One of the AS constructed by students and producing rebuttal is in AS-3 in Figure 8. Students produce rebuttal use $x=\frac{1}{2}$ as a counterexample and make conclusions. The student concludes that the given statement $f(x) \geq g(x)$ for all real numbers is false, since there is $x=\frac{1}{2}$ causing $x \geq x^{2}$ or $f(x)<g(x)$. The counterexample is obtained not by a deductive warrant, but based on the backing of selected samples based on the grouping of real numbers that have been made. In Figure 9, there is a well-defined argumentation structure consisting of all Toulmin's argument components, i.e. data, warrant, backing, claims, qualifiers, and rebuttal.

\section{Example as an Conviction Tool}

Two activities pertaining argumentation in mathematical proving are (1) constructing arguments to gain confidence with respect to truthful statements and (2) intensive reading of the argument to evaluate how to convince others (Inglis \& Mejia-Ramos, 2010). The example used as a convictional tool is an example that 
appears after the final claim is generated. The example used as a convictional tool can be an example that has been used in the beginning, either as a warrant or backing or also a new instance that is re-selected to verify the conjecture that has been produced and convince himself as well as others about the truth of the claim which has been generated. Some argue to convince others of the truth of the claim or to demonstrate the validity of the argument (Inglis \& Mejia-Ramos, 2010). Checking the justification to check whether justification is convincing can be a very difficult job (Mason et al., 2010) so not everyone does it.

The results of observations and interviews reveal the use of examples as a conviction tool by Billy after generating claims that statements are false (the first problem). When observing, the researcher found that Billy used a deductive warrant (Figure $7 \mathbf{b}$ ) to investigate the truth of the statement and justify it, then Billy evaluated his work by rereading several times and writing 'example' with some numbered examples. In the interview, Billy reveals the reason for adding a number example in his work.

Billy: this is a example ma'am, meaning for this first (while pointing to the first case he made: $x>0$ ) I suppose $x=1$ and $x=2$. 1 squared is 1 , mean the same; while 2 is squared is $4,4>2$. If this one (while pointing to his writing on example: $1>-1$ ) for $x<0$.

Interviewer: Why did you make this example?

Billy: I'm just a check, ma'am, like the test

Interviewer: why use an example? You said the example is not proof

Billy: Just wants to reassure maam, there's already an example of a denial, so I use an example to make it easy to count to make sure

The above interview shows that Billy initially used the integer properties for both cases $(x \geq 0$ and $x<0)$ but when doing the evaluation he was less sure that he used the number examples for both selected cases. Conviction occurs at the review stage (Mason et al., 2010) characterized by examining or reviewing the work (Polya in Kennedy, Tipps, \& Johnson, 2008). The example is used as a conviction tool to convince himself and once he is sure, he tries to convince others (researchers). According to Mason et al. (2010), it is fatal not to test the conjecture, ie the process of identifying the guiding error to correct the conjecture. The problem is that when conjectures look plausible and are produced after a long struggle, one would think the conjecture is obviously correct and it would be difficult not to disbelieve it. Actively looking for examples that reject conjectures and learn to critically examine our work and the opinions of others is important.

The importance of the example as a conviction tool is also shown by Yedija in his attempt to investigate the truth of the conjecture (find a counterexample). Initially, Yedija used inductive warrants with example as an investigative and justification tool based on special cases and produced a claim (the first problem) that the statement is false because there is a counterexample that is $x=\frac{1}{2}$. Then to convince himself, on the observation and think aloud it appears that Yedija takes examples of the other numbers $x=\frac{1}{3}, \frac{1}{4}, \frac{1}{5}$ substitutes (without writing) and the more confident the qualifier will claim. Yedija then makes a generalization for counterexample that is obtained is a statement is false because there is a real number $x=\frac{1}{a}$ for an integer that causes $x^{2}<x$. In the interview Yedija reveals that if $x=\frac{1}{a}$ then $x^{2}=\frac{1}{a^{2}}$ and since a integer then $a^{2} \geq a$ so $\frac{1}{a^{2}}<\frac{1}{a}$, it means $x^{2}<x$. The structure of Yedija's argument can be illustrated in Figure 10. 


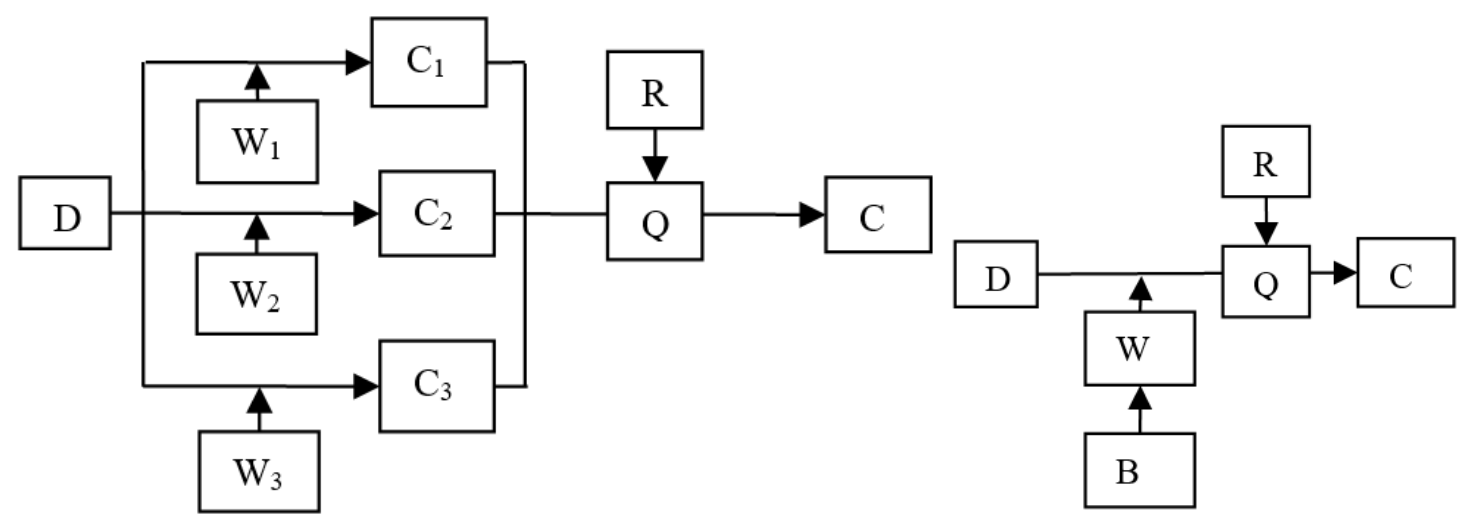

(a)

(b)

Figure 10. Argumentation Structure with an example as Conviction tool

\section{CONCLUSION}

When the problem of proof is considered the student is too abstract, the example is used to understand all the information contained in the problem. Students use the example of the thought experiment by making a representation of all the information obtained to explore what is known and what will be proven. The definition of compositional function and one-on-one functions is not well remembered but the example diagrams stored in students' memories help them to concretize problems in the form of the experiment. The example used in exploring the problem produces only a conjecture and must be deductively proven. The conclusion is not yet valid but it becomes a 'bridge' which enables students to construct a further deductive proof based on the conjecture that has been produced. Exploration places the example as a data component and generates a simple argumentation structure consisting of data, warrant, claim and backing.

Another form of example that students use is an example of numbers and calculations that aim to investigate and justify. Example numbers are used to simplify complex problems. Real numbers that are too broadly simplified by taking some example numbers for each subset of real numbers then using the 'trial and error' method. The student conducts an investigation based on the selected example number and makes justification after using the deductive warrant of a number and operational properties. Investigations and justifications generate some initial claims before they arrive at the final claim. An example of a number in a statement is false, resulting in a true claim (the withdrawal of true conclusion) with deductive proof through a counterexample. However, a statement of false value only produces a conjecture that must be deductively proven. When a student uses a deductive warrant in the form of properties of a real number, the example number appears as a backing example; whereas if the student uses inductive warrant in the form of example number, then backing that appears is rule backing. Thus, the example can serve as a warrant and also backing and plays an important role in generating a true claim on a false statement (disproved).

The role of the example as an investigative and justification tool has implications for the resulting argumentation structure. If the statement is false (disproved) then the example directly generates counterexample and forms the argument structure with one cycle that directly produces the correct final claim; whereas if the statement is true (proved) then the example only produces the conjecture so that there will be a second argument cycle containing deductive proof. The argument structure constructed by students is an updated structure marked by the emergence of new argument components in the second cycle.

Example of numbers is also used when students are in doubt with initial claims that have been generated based on an inductive warrant. Students try to convince themselves and others against the claims that are generated by using examples of numbers and examples of diagrams. Examples of numbers occur in the review phase aimed at checking the validity of claims. The validation results with the examples add to the students' beliefs about the claims they have generated and caused the qualifier changes from possible to even more certain. This also results in the formation of the second cycle argument structure by generating a new inductive warrant in the form of an example of numbers and also a new qualifier. 


\section{Disclosure statement}

No potential conflict of interest was reported by the authors.

\section{Notes on contributors}

Christina M. Laamena - Graduate Students of State University of Malang and Mathematics Education, Pattimura University, Ambon, Indonesia.

Toto Nusantara - Professor State University of Malang, Indonesia.

Edy Bambang Irawan - State University of Malang, Indonesia.

Makbul Muksar - State University of Malang, Indonesia.

\section{REFERENCES}

Aberdein, A. (2012). The parallel structure of mathematical reasoning. In A. Aberdein \& J. Dove (Eds.), The argument of mathematics (pp. 351-370).

Alcock, L., \& Inglis, M. (2008). Doctoral students' use of examples in evaluating and proving conjectures. Educational Studies in Mathematics, 69(2), 111-129. https://doi.org/10.1007/s10649-008-9149-x

Balacheff, N. (1988). Aspects of proof in pupils' practice of school mathematics. In Mathematics, Teachers and Children (pp. 216-235). Hoodes \& Stoughton: Londers.

Boero, P., Garuti, R., \& Mariotti M, A. (1996). Some dynamic mental processes underlying producing and proving conjectures. In O. Figueras, J. L. Cortina, S. Alatorre, T. Rojano, \& A. Sepúlveda (Eds.), Proceedings of the 20th Conference of the International Group for the Psychology of Mathematics Education PME-XX, vol. 2 (pp. 121 - 128). Valencia.

Bromley, D. B. (1986). The case-study method in psychology and related disciplines. New Jersey, USA: John Wiley \& Sons.

Buchbinder, B., \& Pedemonte O. (2011). Examining the role of examples in proving processes through a cognitive lens : the case of triangular numbers, 257-267. https://doi.org/10.1007/s11858-011-0311-z

Cañadas, M. C., Castro, E., \& Castro, E. (2009). Using a model to describe students' inductive reasoning in problem solving.

Conner, A., Singletary, L. M., Smith, R. C., Wagner, P. A., \& Francisco, R. T. (2014). Identifying Kinds of Reasoning in Collective Argumentation. Mathematical Thinking and Learning, 16(3), 181-200. https://doi.org/10.1080/10986065.2014.921131

De Villiers, M. D. (1990). The role and function of proof in mathematics. Pythagoras, 24, 17-24.

Douek, N. (1999). Some Remarks About Argumentation And Mathematical Proof And Their Educational Implications. In I. Schwank (Ed.), European Research in Mathematics Education I (pp. 125-139). Forschungsinstitut fur mathematikdidaktik, Osnabruck.

Ellis, A. E., Lockwood, E., Williams, C. C. W., Dogan, M. F., \& Knuth, E. (2012). Middle school students' example use in conjecture exploration and justification. In Proceedings of the 34th Annual Meeting of the North American Chapter of the Psychology of Mathematics Education.

Fraenkel, J. R., \& Wallen, N. E. (2003). How to design and evaluate research in education. New York, USA: McGraw-Hill Higher Education.

Harel, G., \& Sowder, L. (1998). Students' proof schemes: Results from exploratory studies. Research in Collegiate Mathematics Education III, 234-283. https://doi.org/10.1090/cbmath/007/07

Healy, L., \& Hoyles, C. (2000). A study of proof conceptions in algebra. Journal for Research in Mathematics Education, 396-428. https://doi.org/10.2307/749651

Iannone, P., Inglis, M., Mejia-Ramos, J. P., Simpson, A., \& Weber, K. (2012). Does Generating Examples Aid Proof Production? Educational Studies in Mathematics, 77(1), 1-14. https://doi.org/10.1007/s10649-0119299-0

Inglis, M., \& Mejia-Ramos, J. P. (2010). The Effect of Authority on the Persuasiveness of Mathematical Arguments. Cognition and Instruction, 27(1), 25-50. https://doi.org/10.1080/07370000802584513 
Inglis, M., Mejia-Ramos, J. P., \& Simpson, A. (2007). Modelling Mathematical Argumentation: The Importance. Educational Studies in Mathematics, 66(1), 3-21. https://doi.org/10.1007/s10649-006-90598

Inglis, M., Mejia-Ramos, J. P., \& Simpson, A. (2007). Modelling mathematical argumentation: The importance of qualification. Educational Studies in Mathematics, 66(1), 3-21. https://doi.org/10.1007/s10649-0069059-8

Knipping, C. (2003). Argumentation structures in classroom proving situations. In M. Hanna \& G. Villiers (Eds.), Proceedings of the third congress of the european society for research in mathematics education. Bellaria, Italy, ERME.

Knipping, C. (2004). Argumentation structures in classroom proving situations'. In M. Mariotti (Ed.), Proceedings of CERME (Vol. 3).

Laamena, C. M. (2017). Karakteristik Warrant Dalam Menemukan Counter Example. In Prosiding Seminar Nasional Hasil Penelitian dan Pengabdian kepada Masyarakat. Senasif 2017 (pp. 212-222).

Laamena, C. M., Nusantara, T., Irawan, E. B., \& Muksar, M. (2018). Analysis of the Students' Argumentation based on the level of Ability: Study on the Process of Mathematical Proof Analysis of the Students' Argumentation based on the level of Ability: Study on the Process of Mathematical Proof. Journal of Physics: Conference Series, 1028(1), 0-7.

Lockwood, E., Ellis, A., Knuth, E., Dogan, M. F., \& Williams, C. (2013). Strategically Chosen Examples Leading to Proof Insight: A Case Study of a Mathematician's Proving Process. In Proceedings of the 35th annual meeting of the North American Chapter of the International Group for the Psychology of Mathematics Education (pp. 245-252).

Mason, J., Burton, L., \& Stacey, K. (2010). Thinking mathematically (2nd ed). Harlow: Pearson.

Mason, J., Watson, A., Mason, J., \& Watson, A. (1984). Getting Students to Create Boundary Examples. Retrieved from http://mrbartonmaths.com/resourcesnew/8.\%20Research/Inquries/Getting\%20 students\%20to\%20create\%20Boundary\%20Examples\%20-\%20Watson\%20and\%20Mason.pdf

Mejía-Ramosa, J. P., \& Inglish, M. (2008). What are the argumentative activities associated with proof? In M. Joubert (Ed.), Proceedings of the British Society for Research into Learning Mathematics 28(2) June 2008 (pp. 67-72).

Musser, G. L., Burger, W. F., \& Peterson, B. E. (2011). Mathematics for Elementary Teachers a Contemporary Approach (NINTH EDIT). United States of America: John Wiley \& Sons, Inc.

Nardi, E., Biza, I., \& Watson, S. (2014). What makes a claim an acceptable mathematical argument in the secondary classroom? A preliminary analysis of teachers' warrants in the context of an Algebra Task. In S. Pope (Ed.), British Congress of Mathematics Education (pp. 247-254).

Nardi, E., Biza, I., \& Zachariades, T. (2012). "Warrant” revisited: Integrating mathematics teachers' pedagogical and epistemological considerations into Toulmin's model for argumentation. Educational Studies in Mathematics, 79(2), 157-173. https://doi.org/10.1007/s10649-011-9345-y

Pedemonte, B. (2003). What kind of proof can be constructed following an abductive argumentation. In Proceedings of the Third Conference on European Research in Mathematics Education.

Pedemonte, B. (2007). How can the relationship between argumentation and proof be analysed? Educational Studies in Mathematics, 66(1), 23-41. https://doi.org/10.1007/s10649-006-9057-x

Reid, D. A. (2002). Conjectures and refutations in grade 5 mathematics. Journal for Research in Mathematics Education, 5-29. https://doi.org/10.2307/749867

Toulmin, S. E. (1958). The uses of argument. Cambridge: Cambridge University Press.

Toulmin, S. E. (2003). The Uses of Argument (Second Ed.). Cambridge, UK: Cambridge University Press. https://doi.org/10.1017/CBO9780511840005

Ubuz, B., Dincer, S., \& Bulbul, A. (2012). Argumentation in Undergraduate Math Courses: A Study on Proof Generation. Proceedings of the 36th Conference of the International Group for the Psychology of Mathematics Education, 4, 163-170.

Ubuz, B., Dincer, S., \& Bülbül, A. (2013). Argumentation in Undergraduate Math Courses: A Study on Definition Construction. In A. M. Lindmeier \& A. Heinze (Eds.), Proceedings of the 37th Conference of the International Group for the Psychology of Mathematics Education (pp. 313-320). Kiel, Germany: PME. 
Viholainen, A. (2011). The view of mathematics and argumentation. In E. S. Marta Pytlak, T. Rowland, E. Swoboda Pytlak (Eds.), European Society for Research in Mathematics 7. Rzeszów, Poland.

Watson, A., \& Mason, J. (2005). Mathematics as a constructive activity: Learners generating examples. Mahwah, NJ: Erlbaum.

http://www.iejme.com 